\title{
Adequação do hospedeiro e parâmetros relacionados à aptidão de Cotesia glomerata L. (Hymenoptera: Braconidae) em diferentes ínstares de Ascia monuste orseis Godart (Lepidoptera: Pieridae)
}

\author{
Host suitability and fitness-related parameters of Cotesia glomerata L (Hymenoptera: \\ Braconidae) on different instars of Ascia monuste orseis Godart (Lepidoptera: Pieridae)
}

\author{
Mariana Pizzatto ${ }^{*}$, Vanda Pietrowski ${ }^{1}$, Luis Francisco Angeli Alves ${ }^{2}$, Ana Raquel Rheinheimer ${ }^{1}$ \\ แщщ!
}

RESUMO: O estudo teve por objetivo adequar o ínstar do hospedeiro Ascia monuste orseis ao parasitismo de Cotesia glomerata e avaliar o desempenho do parasitoide. Foram oferecidas às fêmeas de C. glomerata lagartas de $2^{\circ}, 3^{\circ}, 4^{\circ}$ e $5^{\circ}$ ínstares de $A$. monuste orseis, permitindo-se o parasitismo por duas horas. Subsequentemente, acompanhou-se o desenvolvimento das lagartas que foram alimentadas com seçóes foliares de couve-manteiga. Foram avaliados: a duraçấo de cada ínstar das lagartas, o peso da pupa com quatro dias de idade e a porcentagem de lagartas parasitadas e de mortalidade. Em relação ao parasitoide, foram avaliados: porcentagem de parasitismo; número de parasitoide por hospedeiro; porcentagem de emergência; razão sexual; peso médio da pupa; número de parasitoide por lagarta; período ovo-pupa (POP); período pupal (PP); período ovo-adulto (POA). Os resultados indicaram que o segundo ínstar do hospedeiro $A$. monuste oreseis é o mais apropriado para o parasitismo de C. glomerata por proporcionar maior porcentagem de parasitismo e maior número de descendentes por hospedeiro.

PALAVRAS-CHAVE: controle biológico; parasitoide larval; adaptação do hospedeiro, curuquerê-da-couve.

\begin{abstract}
The study aimed to adapt the instar of host Ascia monuste orseis to the parasitism of Cotesia glomerata and evaluate the parasitoid performance. Females of $C$. glomerata were exposed to $2^{\text {nd }}, 3^{\text {rd }}, 4^{\text {th }}$ and $5^{\text {th }}$ instars larvae of $A$. monuste orseis, allowing parasitism for two hours. Subsequently, the development of caterpillars that were fed with leaf sections of kale was monitored. The duration of each caterpillar instar, the weight of four days-old pupae, the percentage of parasitized caterpillars and mortality were assessed. Despite parasitoids, the following parameters were assessed: percentage of parasitism; number of parasitoids per host; percentage of emergence, sex ratio; average weight of the pupae, number of parasitoids per caterpillar; period egg-pupae; pupal period; and period eggadult. The results indicated that the second instar of host A. monuste oreseis is the most suitable for the parasitism of C. glomerata for providing highest percentage of parasitism and a larger number of offspring per host.
\end{abstract}

KEYWORDS: biological control; larval parasitoid; adaptation of the host; kale leafworm.

\footnotetext{
'Laboratório de Entomologia e Controle Biológico, Universidade Estadual do Oeste do Paraná (UNIOESTE) - Marechal Cândido Rondon (PR), Brasil. ${ }^{2}$ Laboratório de Biotecnologia Agrícola, UNIOESTE - Cascavel (PR), Brasil. Bolsista de Produtividade em Pesquisa/CNPq.

*Autor correspondente: marianapizzatto23@gmail.com

Recebido em: 12/12/2013. Aceito em: 30/10/2015
} 


\section{INTRODUÇÃO}

Cotesia glomerata L. (Hymenoptera: Braconidae) é o principal agente natural de controle do curuquerê-da-couve Ascia monuste orseis Godart (Lepidoptera: Pieridae), considerada uma das principais pragas desfolhadoras de Brassicacea (SANTANA, 2008). Esse endoparasitoide gregário está associado a muitas espécies de hospedeiros pertencentes à família Pieridae (Mattiacci; Dicke, 1995).

Os parasitoides são extremamente especializados nas relações com seus hospedeiros e, considerando que seus descendentes se desenvolvem sobre um único hospedeiro, estando restritos aos nutrientes deste, as fêmeas apresentam elevada capacidade de avaliar a adequabilidade do hospedeiro, uma vez que esse fator pode afetar profundamente o desempenho da sua prole (Harvey, 2005; Harvey et al., 2012). Essa avaliação permite ao parasitoide se defender do sistema imunológico e de toxinas deletérias do hospedeiro, competir com outros parasitoides e avaliar a adequabilidade nutricional do hospedeiro (VINSON; Iwantsch, 1980; Lavine; Strand, 2002).

Contudo, em condiçôes nas quais as fêmeas ovipositam em hospedeiros considerados não adequados, os parasitoides adotam estratégias que otimizam o desenvolvimento, tais como alocar ovos que originarão machos, reduzir o número de descendentes ou acelerar seu desenvolvimento larval (Hu et al., 1986; Doetzer; Forester, 1999; Cônsoli; Vison, 2009). Um dos primeiros fatores avaliados pela fêmea para definir a adequabilidade do hospedeiro é a fase de desenvolvimento em que este se encontra.

Hospedeiros, quando estão nos últimos ínstares, apresentam maior disponibilidade de nutrientes aos parasitoides (Murillo et al., 2013); contudo, apresentam maior capacidade de encapsulação, como observado para lagartas de Pieres rapae L. (Lepidoptera: Pieridae), P. brassicae L. (Lepidoptera: Pieridae) e P. napi L. (Lepidoptera: Pieridae) parasitadas por C. glomerata, sendo significativamente maior em lagartas de $2^{\circ}$ e $3^{\circ}$ ínstares de $P$. rapae (Hu et al., 1986; Brodeur; Vet, 1995; Mattiacci; Dicke, 1995; Strand; Pech, 1995; Doetzer; Foerster, 1999). Por outro lado, embora lagartas nos primeiros ínstares apresentem menor disponibilidade de alimento, os parasitoides se defendem com maior facilidade do processo de encapsulação realizado pela lagarta hospedeira (Strand; Pech, 1995).

Para se defenderem da encapsulação, os parasitoides utilizam teratócitos, sendo que nas lagartas mais desenvolvidas a utilização dessas células será maior, para defesa, e, consequentemente, a disponibilidade para a nutrição será menor (DovER et al., 1995; Mattiacci; Dicke, 1995; Firlej et al., 2007), comprometendo, assim, a viabilidade do parasitoide, o que pode levar a uma preferência por parasitar lagartas em ínstares iniciais. Em trabalhos com C. glomerata em lagartas de P. brassicae, o parasitoide completou seu desenvolvimento em todos os cinco ínstares do hospedeiro, com preferência por lagartas de $1^{\circ}$ e início de $2^{\circ}$ ínstares (Laing; Levin, 1982; Mattiacci; Dicke, 1995). Já Apanteles ayerza Brethes (Hymenoptera: Braconidae) em lagartas de $A$. monuste orseis apresentou maior percentual de parasitismo em lagartas de $2^{\circ}$ e $3^{\circ}$ ínstares e náo parasitou lagartas de $4^{\circ}$ e $5^{\circ}$ ínstares (GobBi; Cunha, 1983).

Os parasitoides também tendem a alterar o comportamento alimentar dos hospedeiros, adequando-o as suas necessidades. Lagartas de $A$. monuste orseis parasitadas por $C$. glomerata apresentaram maior consumo alimentar em relação as não parasitadas (GobBi et al., 1989; HasAn; ANSARI, 2012). Scaglia et al. (2003) observaram também a redução da quantidade de proteínas na hemolinfa e o alongamento do ciclo da lagarta.

Apesar da importância do parasitismo natural de C. glomerata sobre lagartas de $A$. monuste orseis, estudos que abordem detalhes dessa interação são escassos no Brasil. Portanto, o objetivo deste trabalho foi adequar o ínstar do hospedeiro de Ascia monuste orseis ao parasitismo de Cotesia glomerata e avaliar o desempenho do parasitoide.

\section{MATERIAL E MÉTODOS}

Para realização do experimento e alimentação do hospedeiro, foram plantadas mudas de couve-manteiga (Brassica oleracea var. acephala L.) em vasos de $4 \mathrm{~L}$ com substrato à base de solo classificado como Latossolo Vermelho Eutroférrico de textura argilosa (EMBRAPA, 2006), composto orgânico e areia, na proporção de 2:1, 5:0,5, respectivamente, e mantidas em casa de vegetação. A criação de $A$. monuste orseis iniciou-se a partir de lagartas coletadas no campo e em laboratório; os adultos foram alimentados com soluçáo aquosa de mel 10\%, e as lagartas, com folhas de couve-manteiga. A criação do parasitoide $C$. glomerata teve início a partir de lagartas parasitadas coletadas em propriedades com sistema de produção agroecológico e que foram mantidas em laboratório sobre lagartas de $A$. monuste orseis oriundas da criação.

$\mathrm{O}$ experimento foi realizado em câmara climatizada tipo BOD $\left(26 \pm 2^{\circ} \mathrm{C}\right.$ e fotofase de $\left.14 \mathrm{~h}\right)$. Lagartas de $2^{\circ}, 3^{\circ}, 4^{\circ} \mathrm{e}$ $5^{\circ}$ ínstares, oriundas da criação massal, foram individualizadas em copos plásticos com capacidade de $80 \mathrm{~mL}$, fechados com tecido tipo voile, preso por elástico, e alimentadas com uma seção foliar de $4 \times 5 \mathrm{~cm}$ de couve-manteiga. Em cada copo foi liberada uma fêmea do parasitoide, com menos de $24 \mathrm{~h}$ de emergência, alimentada com mel e copulada, permitindo o parasitismo por um período de $2 \mathrm{~h}$. Como testemunha, foram mantidas lagartas dos diferentes ínstares sem o parasitismo. Diariamente, foram realizados: a troca do alimento, a limpeza dos copos e o acompanhamento do desenvolvimento das lagartas e dos parasitoides.

Os parâmetros avaliados do hospedeiro e do parasitoide foram adaptados de Murillo et al. (2013). Para o hospedeiro, 
foram avaliados: a duração de cada ínstar das lagartas submetidas e não submetidas ao parasitismo, o peso de pupas com quatro dias de idade, a porcentagem de lagartas parasitadas, de empupação e da mortalidade corrigida, calculada pela fórmula de Аввотт (1925). Para este experimento foram consideradas lagartas parasitadas somente aquelas nas quais houve saída de lagartas do parasitoide e testemunhas as que não tiveram contato com as fêmeas do parasitoide.

Em relação ao parasitoide, foram avaliados a porcentagem de emergência, a razão sexual (RS), o peso médio de pupa (PMPP), determinada pela fórmula

$$
P M P P=\frac{P T M P}{N P M} \times 100
$$

(onde PTMP = peso da massa de pupa e NPM = número de pupas da massa), o número de parasitoides por lagarta, o período ovo-pupa (POP), o período pupal (PP) e o período ovo-adulto (POA).

O delineamento experimental utilizado foi inteiramente casualizado com 3 repetiçóes para cada ínstar, tanto para lagartas parasitadas como para não parasitadas (testemunha), sendo que cada repetição consistiu de 12 copos com uma lagarta por copo.

Para análise de desenvolvimento das lagartas, utilizou-se análise da variância (ANOVA) para medidas repetidas; para tempo total de cada ínstar, utilizou-se ANOVA fatorial, em que os fatores de análise foram o ínstar de parasitismo e os estados da lagarta (não parasitadas, parasitadas e testemunha), utilizando-se o software Statistica 7 (STATsoft Inc., 2006). Em relação aos demais parâmetros avaliados, realizou-se ANOVA, sendo as médias comparadas pelo teste de Tukey $(\mathrm{p}<0,05)$, utilizando-se o software Assistat (Silva; Azevedo, 2009).

\section{RESULTADOS}

Observou-se aumento no tempo de desenvolvimento do hospedeiro quando o parasitoide conseguiu se desenvolver e as lagartas foram parasitadas no $2^{\circ}, 3^{\circ}$ e $4^{\circ}$ ínstares (Figs. 1A, 1B, 1C e 2).

Analisando o desenvolvimento dos ínstares em lagartas parasitadas, náo parasitadas e testemunha, notou-se que houve padrão de comportamento do hospedeiro em relação ao seu desenvolvimento, independentemente do ínstar em que ocorreu o parasitismo.

Quando as lagartas foram oferecidas aos parasitoides no $2^{\circ}$ ínstar, não houve diferença na duração do $3^{\circ}$ ínstar entre parasitadas $(2+0,07$ dias) e não parasitadas $(1,9+0,08$ dias $)$, porém ambas diferiram da testemunha $(1,4+0,09$ dias $)$ (Fig. 1A). No $4^{\circ}$ ínstar, lagartas parasitadas $(2,5+0,17$ dias $)$ diferiram estatisticamente da testemunha $(1,9+0,97$ dias $)$ e não diferiram das lagartas não parasitadas $(2+0,12$ dias $)$. Quando no $5^{\circ}$ ínstar, lagartas parasitadas $(8,3+0,30$ dias $)$ diferiram da testemunha $(4,4+0,09$ dias $)$ e das náo parasitadas $(4,5+0,18$ dias), que, por sua vez, não diferiram entre si. Com isso, notou-se que quando as lagartas foram parasitadas no $2^{\circ}$ ínstar, houve acréscimo significativo no tempo de duração do $4^{\circ}$ e $5^{\circ}$ ínstares.

Quando as lagartas foram submetidas ao parasitismo no $3^{\circ}$ ínstar (Fig. 1B), observou-se que não houve diferença no desenvolvimento de lagartas parasitadas, náo parasitadas e testemunha para o $4^{\circ}$ ínstar; entretanto, no $5^{\circ}$ ínstar lagartas parasitadas $(7+0,21$ dias $)$ apresentaram diferença significativa em relaçáo à testemunha $(5,1+0,15$ dias $)$, náo diferindo das não parasitadas, que, por sua vez, não diferiram da testemunha.

Lagartas submetidas ao parasitismo no $4^{\circ}$ ínstar (Fig. 1C) não apresentaram diferença significativa entre parasitadas, não parasitadas e testemunha nesse ínstar. Contudo, no $5^{\circ}$ ínstar observou-se que as lagartas parasitadas $(10+0,21$ dias $)$ diferiram das não parasitadas $(4,6+0,30$ dias $)$ e da testemunha $(4,3+0,15$ dias $) ;$ no entanto, essas duas últimas não diferiram entre si. Quando expostas ao parasitoide no $5^{\circ}$ ínstar (Fig. 1D), não foram obtidas lagartas parasitadas, sendo que lagartas não parasitadas $(3,8+0,05$ dias $)$ e testemunha $(3,7+0,07$ dias $)$ não apresentaram diferença entre si.

Considerando a duração total da fase de larval após o parasitismo (Fig. 2), observou-se que, quando as lagartas foram parasitadas no $2^{\circ}$ ínstar, houve alongamento no desenvolvimento, com duração média de $13 \pm 0,16$ dias, diferindo da testemunha (8,6 $\pm 0,16$ dias) e das lagartas não parasitadas (8,5 $\pm 0,16$ dias). Quando as lagartas foram submetidas ao parasitismo no $3^{\circ}$ ínstar, esse alongamento de ciclo não ocorreu, não havendo diferença significativa entre lagartas parasitadas (8 $\pm 0,21$ dias), não parasitadas ( $8,1 \pm 0,64$ dias) e testemunha $(6,9 \pm 0,18$ dias). Lagartas submetidas ao parasitismo no $4^{\circ}$ ínstar aumentaram significativamente seu tempo de desenvolvimento (12,6 $\pm 0,21$ dias), quando comparadas às lagartas não parasitadas $(7,7 \pm 0,34$ dias) e à testemunha $(6,8 \pm 0,14$ dias), sendo que essas duas últimas não diferiram entre si. Para lagartas parasitadas em $5^{\circ}$ ínstar, não se observou diferença significativa entre testemunha (3,7 $\pm 0,07$ dias) e não parasitada (3,8 $\pm 0,05$ dias) na duração média do ínstar (Fig. 2).

Em relação ao peso das pupas provenientes de lagartas não parasitadas e testemunhas, houve diferença significativa apenas quando a lagarta foi oferecida ao parasitoide no $4^{\circ}$ ínstar (Tabela 1), sendo que o peso da pupa dessas lagartas também diferiu significativamente das ofertadas aos parasitoides no $2^{\circ}$ e $5^{\circ}$ ínstares, indicando que quando o parasitismo ocorreu nesse ínstar, provavelmente tenha havido maior gasto energético para eliminar o parasitoide.

Para os parâmetros do parasitoide, de modo geral, houve variação nos resultados dependendo do ínstar de parasitismo. A porcentagem de parasitismo diminuiu com o aumento do 

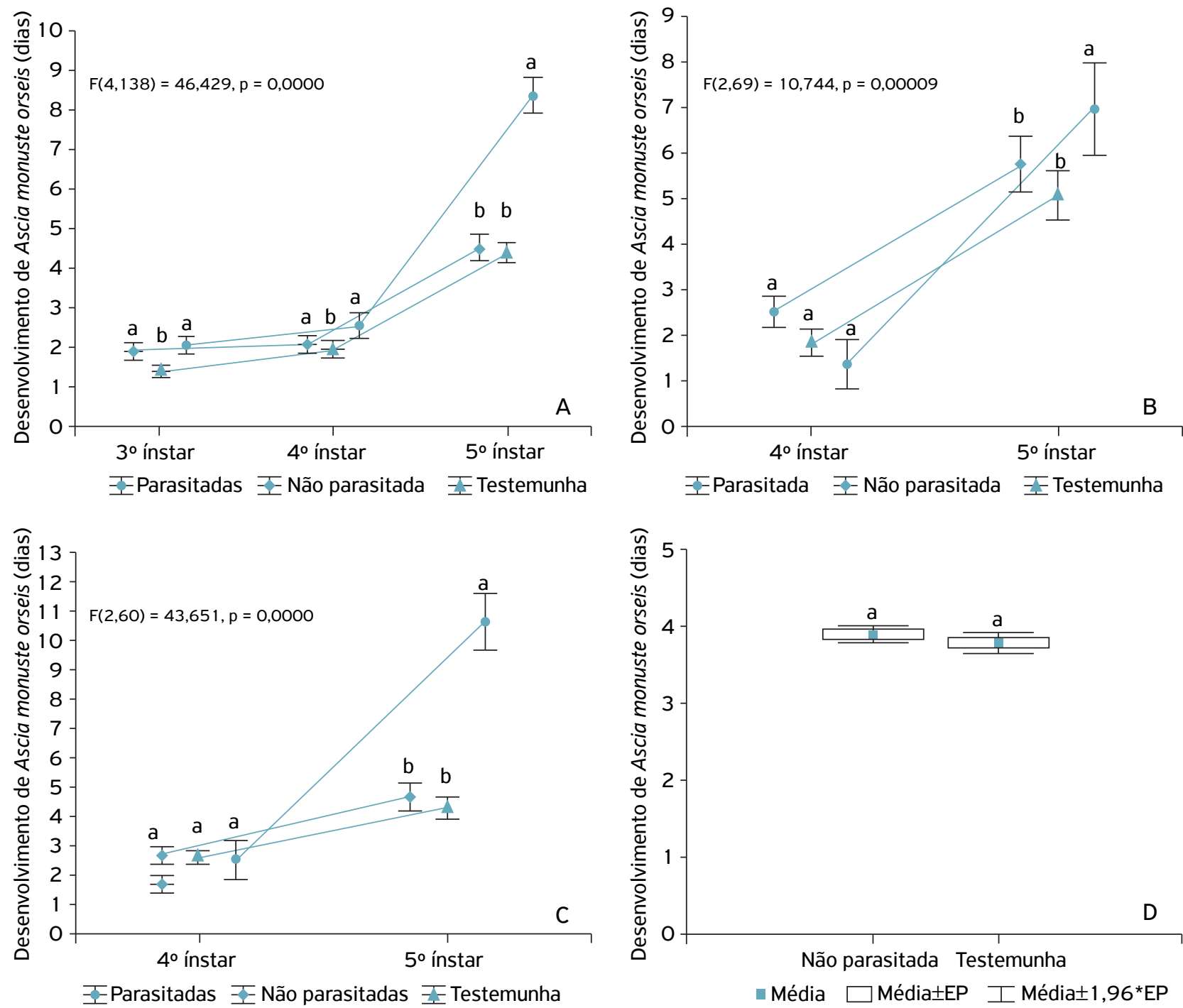

Figura 1. Duração média $( \pm \mathrm{IC}$ ) de ínstares de Ascia monuste orseis submetidas ao parasitismo de Cotesia glomerata em diferentes ínstares: $2^{\circ}(A), 3^{\circ}(B), 4^{\circ}(C)$ e $5^{\circ}(D)$.

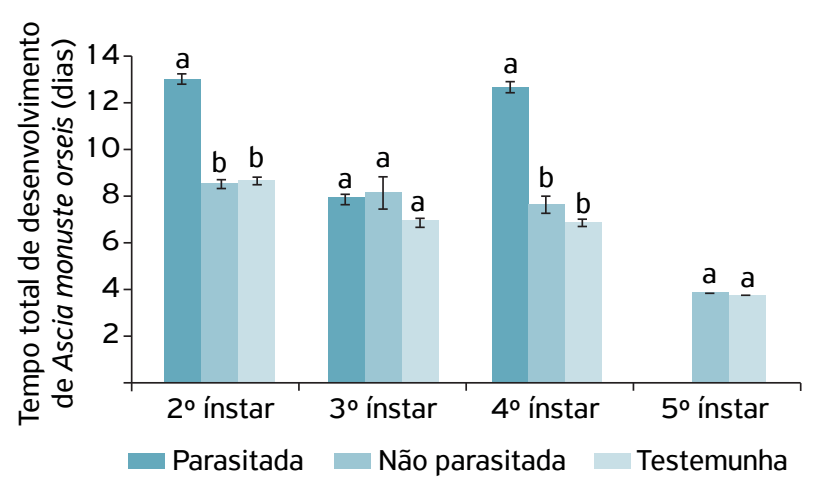

Figura 2. Duração total (dias $\pm \mathrm{EP}$ ) da fase larval de Ascia monuste orseis após o parasitismo, nos diferentes ínstares, por Cotesia glomerata. ínstar e, consequentemente, do tamanho da lagarta oferecida ao parasitoide, sendo similar entre o $2^{\circ}$ e $3^{\circ}$ ínstares e diferente entre o $2^{\circ}$ e $4^{\circ}$ ínstares, indicando uma maior adequabilidade do hospedeiro no $2^{\circ}$ ínstar. Contudo, não houve diferença significativa para a porcentagem de mortalidade do hospedeiro e de lagartas que empuparam (Tabela 2).

Quanto ao número de parasitoides por hospedeiro, novamente tem-se a melhor adequabilidade das lagartas de $2^{\circ}$ ínstar, uma vez que o número de parasitoide por hospedeiro foi significativamente maior quando o parasitismo ocorreu nesse ínstar, diferindo daqueles em que o parasitismo ocorreu em lagartas de $3^{\circ}$ e $4^{\circ}$ ínstares. Contudo, independentemente do ínstar em que ocorreu o parasitismo, a porcentagem de emergência dos parasitoides foi semelhante (Tabela 2). 
Tabela 1. Peso (mg) de pupas de Ascia monuste orseis oriundas do insucesso do parasitismo por Cotesia glomerata nos diferentes ínstares.

\begin{tabular}{|c|c|c|c|c|c|c|c|}
\hline \multirow{2}{*}{ Variáveis } & \multicolumn{4}{|c|}{ Ínstar de exposição ao parasitoide } & \multirow{2}{*}{ Valor $\mathrm{p}$} & \multirow{2}{*}{$\mathbf{F}$} & \multirow{2}{*}{$\mathrm{C} \%$} \\
\hline & $2^{\circ}$ & $3^{\circ}$ & $4^{\circ}$ & $5^{\circ}$ & & & \\
\hline Pupas do parasitismo* & $386,8 \pm 14 \mathrm{~A} a$ & $349,4 \pm 15 \mathrm{ABa}$ & $304,9 \pm 19 \mathrm{Bb}$ & $390,2 \pm 4 \mathrm{Aa}$ & $>0,05$ & 3,11 & 3,37 \\
\hline Pupas testemunhas & $379,6 \pm 7 a$ & $386,0 \pm 6 a$ & $384,4 \pm 5 a$ & $400,0 \pm 4 a$ & & & \\
\hline $\mathrm{P}$ & $<0,05$ & $<0,05$ & $>0,05$ & $<0,05$ & & & \\
\hline $\mathrm{F}$ & 0,13 & 6,7 & 0,2 & 0,84 & & & \\
\hline CV\% & 1,68 & 5,56 & 5,66 & 0,97 & & & \\
\hline
\end{tabular}

Médias ( \pm EP) seguidas pela mesma letra minúscula na coluna e maiúscula na linha não diferem entre si pelo teste de Tukey $(p<0,05)$.

*Pupas oriundas de lagartas submetidas ao parasitismo, onde não ocorreu desenvolvimento do parasitoide.

Tabela 2. Desempenho de Cotesia glomerata parasitando diferentes ínstares de Ascia monuste orseis.

\begin{tabular}{|c|c|c|c|c|c|c|}
\hline \multirow{2}{*}{ Parâmetros } & \multicolumn{4}{|c|}{ Ínstar Ascia monuste orseis } & \multirow{2}{*}{ Valor $p$} & \multirow{2}{*}{ CV\% } \\
\hline & $2^{\circ}$ ínstar & $3^{\circ}$ ínstar & $4^{\circ}$ ínstar & $5^{\circ}$ ínstar & & \\
\hline Parasitismo (\%) & $36,1 \pm 2,77 a$ & $27,7 \pm 2,77 a b$ & $16,6 \pm 4,81 b$ & - & $<0,005$ & 14,69 \\
\hline Mortalidade do hospedeiro (\%) & $38,8 \pm 2,77 a$ & $44,4 \pm 10,01 a$ & $38,8 \pm 2,77 a$ & - & $>0,05$ & 26,41 \\
\hline Empupação do hospedeiro (\%) & $61,1 \pm 4,80 b$ & $55,5 \pm 4,80 \mathrm{~b}$ & $61,6 \pm 4,40 b$ & $100 \pm 0,0 \mathrm{a}$ & $<0,001$ & 5,82 \\
\hline NMPL & $67,3 \pm 9,52 a$ & $39,7 \pm 2,41 b$ & $21,7 \pm 4,44 b$ & - & $<0,05$ & 25,10 \\
\hline \% emergência & $96,8 \pm 0,41 a$ & $95,6 \pm 2,33 a$ & $96,9 \pm 1,54 a$ & - & $>0,05$ & 0,77 \\
\hline Razão sexual & $0,4 \pm 0,06 a b$ & $0,5 \pm 0,01 a$ & $0,2 \pm 0,12 b$ & - & $<0,05$ & 14,69 \\
\hline PMP (mg) & $2,4 \pm 0,2 a b$ & $2,8 \pm 0,3 a$ & $1,6 \pm 0,1 b$ & - & $>0,05$ & 15,29 \\
\hline \multicolumn{7}{|l|}{ Tempo de desenvolvimento (dias) } \\
\hline POP & $11,5 \pm 0,41 a$ & $10,4 \pm 0,30 a$ & $10,3 \pm 0,33 a$ & - & $>0,05$ & 7,25 \\
\hline PP & $5,3 \pm 0,16 a$ & $4,7 \pm 0,38 a b$ & $4,0 \pm 0,00 \mathrm{~b}$ & - & $<0,05$ & 4,53 \\
\hline POA & $16,9 \pm 0,36 a$ & $15,1 \pm 0,08 a$ & $14,8 \pm 0,11 a$ & - & $>0,05$ & 32,82 \\
\hline
\end{tabular}

Médias ( \pm EP) seguidas pela mesma letra minúscula na linha não diferem entre si pelo teste de Tukey a $5 \%$ de probabilidade de erro. PMP: peso médio da pupa; NMPL: número médio de pupa por lagarta; POP: período ovo-pupa; PP: período pupal; POA: período ovo-adulto.

A razão sexual dos parasitoides diferiu significativamente entre o $3^{\circ}$ e $4^{\circ}$ ínstares, porém nenhum dos dois diferiu do $2^{\circ}$ ínstar (Tabela 2). A maior proporção de machos nos parasitoides oriundos de lagarta parasitadas no $4^{\circ}$ ínstar levou a um menor peso médio de pupa, sendo significativamente inferior para as pupas de $C$. glomerata originárias de lagartas parasitadas no $3^{\circ}$ ínstar. Náo se observou diferença do $3^{\circ}$ e $4^{\circ}$ ínstares para as pupas de parasitoide oriundos de lagartas parasitadas no $2^{\circ}$ ínstar (Tabela 2).

Quanto às fases de desenvolvimento do parasitoide, no geral não houve diferença entre os parasitoides oriundos de lagartas parasitadas no $2^{\circ}, 3^{\circ}$ ou $4^{\circ}$ ínstares, havendo diferença significativa apenas para duraçáo do PP entre o $2^{\circ}$ e $4^{\circ}$ ínstares (Tabela 2).

\section{DISCUSSÃO}

Os resultados deste trabalho indicaram que ocorreu impacto do parasitismo sobre o hospedeiro, uma vez que houve aumento no tempo de desenvolvimento das lagartas quando estas foram parasitadas, variando esse aumento de 1,5 vezes em lagartas parasitadas no $2^{\circ}$ ínstar a 1,6 vezes para lagartas parasitadas no $4^{\circ}$ ínstar (Fig. 2). Esses resultados corroboram os obtidos por Scaglia et al. (2003), que observaram um acréscimo de um dia no desenvolvimento de $A$. monuste orseis quando parasitada por $C$. glomerata. Notou-se, pelos resultados apresentados, que a alteração no desenvolvimento do hospedeiro não ocorreu no ínstar em que houve o parasitismo, isso provavelmente ocorreu pelo fato de o parasitoide estar na fase de ovo e no primeiro ínstar, não sendo capaz de afetar o hospedeiro nessa fase (GobBi et al., 1989; HasAn; AnsARI, 2012).

Os parasitoides conhecidos como coinobiontes, como C. glomerata, têm como uma das estratégias de sobrevivência alterar o desenvolvimento de seu hospedeiro, no intuito de finalizar seu ciclo, aumentando o tempo em que a lagarta fica se alimentando e, consequentemente, tendo um maior tempo para se alimentar e obter os nutrientes necessários ao seu desenvolvimento (Hu et al., 1986; Doetzer; Forester, 1999; SCaglia et al., 2003; Cônsoli; Vison, 2009).

Outro fator que pode ter levado ao aumento na duração dos ínstares das lagartas submetidas ao parasitismo, observado neste trabalho (Figs. 1 e 2), é o gasto energético utilizado pelo hospedeiro em seu processo de defesa, a fim de eliminar o parasitoide, utilizando como principal meio para isso 
a encapsulaçáo (Mattiacci; Dicke, 1995). Strand; Pech (1995) definiram três fases para o encapsulamento do parasitoide, sendo que em todas há exigência de maior consumo energético por parte do hospedeiro. Esse processo de resposta imunológica torna-se mais eficiente à medida que a lagarta vai se desenvolvendo, sendo que lagartas hospedeiras dos últimos ínstares apresentam maior capacidade de encapsulação (Hu et al., 1986; Brodeur; Vet, 1995).

A baixa capacidade de encapsulaçáo dos hospedeiros nas fases iniciais e, consequentemente, a maior adequabilidade de lagartas de $2^{\circ}$ e $3^{\circ}$ ínstares, como a observada neste trabalho (Tabela 2), assemelham-se aos resultados observados por Geervliet et al. (1993) e por Mattiacci; Dicke (1995) com essa espécie de parasitoide utilizando como hospedeiro lagartas de $P$. brassicae, $P$. rapae e $P$. rapi, havendo preferência do parasitoide por hospedeiros nos ínstares iniciais. Em lagartas de A. monuste orseis, Gobвi; Cunha (1983) também observaram preferência para o parasitismo de A. yerzia nos 3 primeiros ínstares; contudo, esses autores obtiveram uma maior porcentagem de parasitismo (50\%), quando comparada com os resultados do parasitismo médio deste trabalho $(26,8 \%)$.

Assim, em relação ao desenvolvimento do hospedeiro, pode-se observar que o impacto do parasitismo foi manifestado pelo alongamento na duração dos ínstares subsequentes ao parasitismo, sendo maior quando o parasitismo ocorreu no $4^{\circ}$ ínstar em que, embora tenha havido aumento na duração do ínstar, o peso final da pupa foi inferior ao oriundo de lagarta não parasitada, indicando perda energética na eliminação do parasitoide.

\section{CONCLUSÃO}

A. monuste oseris tem potencial para o desenvolvimento do parasitoide C. glomerata, com maior eficiência quando o parasitismo ocorre em lagartas de $2^{\circ}$ ínstar. No entanto, são necessários novos estudos para que se entenda melhor essa interação.

\section{AGRADECIMENTOS}

À Coordenação de Aperfeiçoamento de Pessoal de Nível Superior (CAPES), pela concessáo de bolsa de mestrado e pelo financiamento de parte da pesquisa.

À Universidade Estadual do Oeste do Paraná (UNIOESTE) - Campus Marechal Cândido Rondon pela disponibilidade intelectual por meio de seus professores e servidores, além do espaço físico para pesquisa.
ABBOTT, W.S. A method of computing the effectiveness of an insecticide. Journal of Economic Entomology, v.18, p.265266, 1925.

BRODEUR, J.; VET, L.E.M. Relationships between parasitoid hosts rang and host defense: a comparative study of egg encapsulation in two related parasitoid species. Physiological Entomology, v.20, p.7-12, 1995.

CÔNSOLI, F.L.; VINSON, S.B. Parasitoides (Hymenoptera). In: PANIZZI, A.R.; PARRA, J.R.P. Bioecologia e nutrição de insetos, capítulo 20, p.837-874, 2009.

DOETZER, A.K.; FOERSTER, L.A. Efeito de diferentes estádios de Pseudaletia sequax Lepidoptera, Noctuide) sobre o parasitismo por Glyptapanteles nuesebecki (Hymenoptera, Braconidae). Revista Brasileira de Entomologia, v.43, p.69-72, 1999.

DOVER, B.A.; MENON, A.; BROWN, R.C.; STRAND, M.R. Suppression of juvenile hormone esterase in Heliothis virescens by Microplitis demolitor calys fluid. Journal Insect Physiological, v.42, n.9, p.809-817, 1995. Disponível em: <http://www.sciencedirect. com/science/article/pii/0022191095000170> Acesso em: 25 jan. 2013.
EMBRAPA. Sistema Brasileiro de Classificação de Solos. Brasília: Embrapa Produção de Informação; Rio de Janeiro: Embrapa Solos; 2006. p.306.

FIRLEJ, A.B.; LUCAS, E.; CODERRE, D.; BOIVIN, G. Teratocytes growth pattern reflects host suitability in a host-parasitoid assemblage. Physiological Entomology, v.32, p.181-187, 2007. Disponível em: <http://onlinelibrary.wiley.com/doi/10.1111/j.13653032.2006.00548.x/abstract>. Acesso em: 22 jan. 2013.

GEERVLIET, J.B.F.; AAKEN, R. van; SAVELKOUL, C.; SMILTTE, S.; BRODEUR, J.; VET, L.E.M.; DICKE, M. Comparative approach to infochemical use by parasitoids for the case of Cotesia glomerata end Cotesia rubecula. Proceedings of the Section Experimental and Applied Entomology of the Netherlands Entomological Society, v.4, p.33-38, 1993. Disponível em: <http://www.researchgate.net/ publication/40160138>. Acesso em: 22 jan. 2013.

GOBBI, N.; JANNINI, A. E.; TAUK, S.M.; FOWLER, H.G.; SILVA, O.A. Efeito do parasitismo de Cotesia glomerata (LINNAEUS, 1758) (HYMENOPTERA, BRACONIDAE) no consumo alimentar de lagartas de Ascia monuste orseis (GODART, 1818) (LEPIDOPTERA, PIERIDAE). Anual da Sociedade Entomológica do Brasil, v.18, p.170-175, 1989. 
GOBBI, N.; CUNHA, M.C.A. Observações preliminares referentes ao relacionamento entre lagartas de Ascia monuste orseis (GODART, 1818) (LEPIDOPTERA, PIERIDAE) e seu parasita Apanteles ayerza (BRETHE, 1920) (HYMENOPTERA, BRACONIDAE). Naturalia, v.8, p.193-196, 1983.

HARVEY, J.A. Factors affecting the evolution of development strategies in parasitoid wasps: the importance of functional constraints and incorporating complexity. Entomologia Experimentalis et Applicata, v.117, p.1-13, 2005. Disponível em: < http://onlinelibrary.wiley.com/doi/10.1111/j.15707458.2005.00348.x/pdf >. Acesso em: 02 fev. 2013.

HARVEY, J.A.; GOLS, R.; VET, L.E.M.; KRUIDHOF, H.M. Development of a hyperparasitoid wasp in different stages of its primary parasitoid and secondary herbivore hosts. Journal of Insect Physiology, v.58, p.1463-1468, 2012. Disponível em: <http://www.ncbi.nlm.nih. gov/pubmed/22939901 >. Acesso em: 29 jan. 2013.

HASAN, F.; ANSARI, S.M.; Superparasitism in Cotesia golomerata does not benfit the host plant by reduction of herbivory caused by Pieris brassicae. Saudi Journal of Biological Sciences, v.19, n. 1, p.65-71, 2012. Disponível em: <http://www.sciencedirect. com/science/article/pii/S1319562X10001130>. Acesso em: 26 out. 2015 .

HU, C.; BARBOSA, P.; MARTINAT, P. Reproductive biology and related host-parasitoid interactions between the gypsy moth, Lymantria dispar and Glyptapanteles flavicoxis, a gregarious endoparasitoid. The Annals of Applied Biology, v.109, n.3, p.485490, 1986.

LAING, J.E.; LEVIN, D.B. A review of the biology and bibliography of Apanteles glomeratas (L.) (Hymenoptera: Braconidae). Biocontrol News Information, v.3, p.7-23. 1982.

LAVINE, M.D.; STRAND, M.R. Insect hemocytes and their role in immunity. Insect Biochemistry and Molecular Biology, v.32, p.1295-1309, 2002. Disponível em: <http://www.ncbi.nlm.nih. gov/pubmed/12225920>. Acesso em: 22 jan. 2013.

MATTIACCI, L.; DICKE, M. The parasitoid Cotesia glomerata (Hymenoptera: Braconidae) discriminates between first and fifth larval instars of its host Pieris brassicae, on the basis of contact cues from frass, silk, and hervibore-damaged leaf tissue. Journal of Insect Behavior, v.8, n.4, p.485-498, 1995. Disponível em:
<http://link.springer.com/article/10.1007\%2FBFO 1995321 \#page-1>. Acesso em: 02 fev. 2013.

MURILLO, H.; HUNT, D.W.A.; VANLAERHOVEN, S. Host suitability, and fitness-related parameters of Campoletis sonorensis (Hymenoptera: Ichneumonidae) as a parasitoid of the cabbage looper, Thichoplusia ni (Lepidoptera: Noctuide). Biological Control, n.64, p. 10-15, 2013. Disponível em: <http://www.sciencedirect. com/science/article/pii/S1049964412002095>. Acesso em: 15 fev. 2013

SANTANA, A.F.K. Performance e preferência de imaturos selvagens de Ascia monuste (GodartGodart, 1819) (Lepidoptera: Pieridae) na mudança e privação de hospedeiros alimentares diferentes. 2008. 77f. Dissertação (Mestrado) - Universidade Federal de Santa Maria, Santa Maria, 2005.

SCAGLIA, M.; BROCHETTO-BRAGA, M.R.; CHAUD-NETTO, J.; GOBBI, N. Haemolymph electrophoretic pattern of Ascia monuste orseis lagartae (Lepidoptera: Pieridae) parasitized by Cotesia glomerata (Hymenoptera: Braconidae). Journal of venomous animals and toxins incluindo doenças tropicais, v.9, n. 1, 2003. Disponível em: <http://scielo.br/scielo.php?script=sci_arttext\&pid=S1678$1992003000100006 \&$ Ing=pt\&nrm=iso\&tlng=en $>$. Acesso em: 03 maio 2011.

SILVA, F.A.S.; AZEVEDO, C.A.V. Principal components Analysis in the Software Assistat-Statistical Attendance. In: World Congress on Computers in Agriculture, 7, Reno-NV-USA: American Society of Agricultural and Biological Engineers, 2009.

STATSOFT, I. Electronic statistics textbook. Tulsa, OK: Author. Retrived Nov. 2006. Disponível em: <http://www.statsoft.com/ textbook/stathome.htm>. Acesso em: 13 nov. 2012.

STRAND, M.R.; PECH, L.L. Immunological basis for compatibility in parasitoid-host relationships. Annual Review of Entomology, v.40, p.31-56, 1995. Disponível em: <http://www.annualreviews.org/ doi/pdf/10.1 146/annurev.en.40.010195.000335>. Acesso em: 20 fev. 2013.

VINSON, S.B.; IWANTSCH, G.F. Host suitability for Insect Parasitoids. Annual Review of Entomology, v.24, p.397-419, 1980. Disponível em: <http://www.annualreviews.org/doi/abs/10.1146/annurev. en.25.010180.002145? journalCode=ento $>$. Acesso em: 20 fev. 2013. 